Check for updates

Cite this: J. Mater. Chem. B, 2018, 6, 2104

\section{The functionalization of natural polymer-coated gold nanoparticles to carry bFGF to promote tissue regeneration $\dagger$}

\author{
Helena Ferreira, (D) *ab Albino Martins, (D) ab Marta L. Alves da Silva, (D) ab \\ Sara Amorim, (D) ab Susana Faria, (D) ${ }^{c}$ Ricardo A. Pires, (D) ab Rui L. Reis (D) ab and \\ Nuno M. Neves (iD *ab
}

\begin{abstract}
Gold nanoparticles (AuNPs) enable the treatment and real-time monitoring of several diseases, providing an exciting and advantageous nanomedicine strategy. These NPs have therefore been adequately functionalized to enable them to carry growth factors (GF), namely basic fibroblastic (bF) GF, which play an essential role in different and important cellular processes including cellular proliferation, survival, migration and differentiation. The AuNPs were coated with natural polymers, chitosan and heparin, to enhance their physicochemical properties such as suspension stability. The polyelectrolyte coating was monitored using a quartz crystal microbalance with dissipation, size and zeta-potential analysis. The natural polymer-coated AuNPs have a spherical shape and a positive surface charge due to chitosan amino groups, enabling their biofunctionalization with monoclonal antibodies to target specific biomolecules. Additionally, cellular assays with the chondrocyte cell line ATDC5 show that the NPs are cytocompatible at relevant concentrations. As a proof of concept of their potential application in tissue regeneration, the natural polymer-coated AuNPs were further functionalized with an antibody to selectively bind the desired GF. The bFGF concentration reached in the NPs without compromising the cytocompatibility demonstrates the potential of this carrier for tissue regeneration.
\end{abstract}

Received 19th December 2017, Accepted 27th February 2018

DOI: $10.1039 / c 7 t b 03273 k$

rsc.li/materials-b research field of theranostics. ${ }^{3}$ Theranostic NPs present unique capabilities, namely non-invasive administration and real-time monitoring of the therapeutic effect or disease evolution, evaluation of the therapeutic agents pharmacokinetic and target site accumulation, adjustment of the dose and administration frequency during the treatment, the ability to track and quantify drug release, and can result in synergistic therapeutic effects of the medicine and the imaging agent (e.g., by light, thermal and photothermal therapies). ${ }^{3-6}$ Theranostic formulations therefore have the potential to translate the current "one-size-fits-all" therapy into truly precision medicine.

Among the numerous imaging agents that have been proposed, gold (Au)NPs have been of particular interest due to their unique properties such as biocompatibility, chemical stability and inertness, easy preparation in a variety of sizes and shapes, effortless surface modification and tunable optical properties. ${ }^{7-10}$ Moreover, they can be detected by a variety of imaging techniques such as $\mathrm{X}$-ray attenuation, ${ }^{11}$ multiwavelength photoacoustic imaging, ${ }^{12}$ surface-enhanced Raman scattering, ${ }^{13}$ near-infrared irradiation ${ }^{14}$ and computed tomographic imaging. ${ }^{15}$ In therapeutics, AuNPs can lead to photodynamic ${ }^{7,16-18}$ or photothermal ${ }^{19-22}$ damage of microorganisms and cancer cells, and they can also be the therapeutic agent themselves. ${ }^{23-25}$ Additionally, AuNPs can serve as a carrier for 


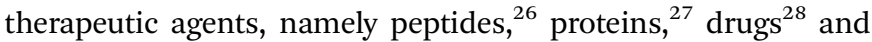
nucleic acids. ${ }^{29,30}$ As a diagnostic tool, these particles can be used in the visualization and bioimaging of several chemical and biological agents, in analytical diagnostic methods (e.g. immunochromatographic tests) and as biosensors (e.g. for diagnosis of infections or detection of toxins in food or biological fluids). ${ }^{7,31}$ AuNPs are therefore a very useful tool to use in diverse clinical conditions. Indeed, despite the huge diversity of metal NPs, AuNPs are among the most used in biological applications. ${ }^{32}$

AuNPs are commonly engineered with a polymeric coating to improve their physicochemical properties. Several natural or synthetic biocompatible polymers have been used to avoid the aggregation of AuNPs, to improve their payloads, to impart biocompatibility, to develop external or internal stimuli triggered systems, and to increase the residence time in the circulation, ${ }^{33-36}$ avoiding early clearance by the reticuloendothelial system. The polymeric coating of AuNPs can be carried out by several methods. ${ }^{33,34}$ The layer-by-layer (LbL) assembly is a simple, reliable, easy, robust, cost-effective and versatile bottom-up technology that has been widely applied to produce a multitude of multi-layered-architectures with nanometer precision and exhibiting different functionalities to target the ultimate and desired application. ${ }^{37-40}$ Moreover, LbL assembly allows the coating of any kind of substrate (e.g. 3-dimensional substrates) of almost any surface chemistry and under environmental friendly experimental conditions, which is extremely important when biomolecules are used. ${ }^{41}$ Consequently, this promising approach surpasses several limitations present in other currently used thin film deposition methods such as dip-coating. ${ }^{41}$ Therefore, in this work, the coating of the AuNPs surface was performed by the LbL methodology using two natural biodegradable polymers, namely, chitosan and heparin. Chitosan is a polycation that is already used in the preparation of biomedical devices since it presents antibacterial activity, ${ }^{42,43}$ hemostatic activity and has the ability to accelerate wound closure and healing. ${ }^{44}$ On the other hand, heparin, a strong polyanion that can promote stronger complexation with chitosan, is a widely used anticoagulant and a highly effective polymer in stabilizing growth factors (GFs) like the basic fibroblast GF (bFGF or FGF-2). ${ }^{45}$ Therefore, the association of biological drugs with a device comprising the intrinsic properties of these two polymers will allow for protection and synergistic therapeutic effects; for example, chitosan-coated AuNPs have antioxidant activity in vivo. ${ }^{46}$

As a proof of concept, and aiming to validate the ability of the developed NPs to serve as a nanoplatform to carry a bioactive factor, the immobilization of a defined antibody that binds bFGF was investigated. This GF has the ability to interact with diverse cell types from the vascular, nervous and connective tissues. ${ }^{47,48}$ bFGF, is in fact, a potent regulator of cell proliferation, differentiation, migration and survival, as well as angiogenesis and wound repair. ${ }^{48-50}$ Nevertheless, bFGF, like other therapeutic agents (such as nucleic acids and peptides), should be administered using an appropriate carrier that allows the enhancement of its half-life and ensures the preservation of its active form. ${ }^{51}$ Therefore, the in vivo administration of bFGF is commonly associated with heparin or heparin sulfate to avoid its physical denaturation and proteolytic degradation. ${ }^{47}$ Moreover, bFGF bound to this glycosaminoglycan seems to be more effective than its uncomplexed analogue. ${ }^{52}$ Indeed, there are several studies in the literature that demonstrate the therapeutic potential of this heparin-binding GF. ${ }^{53-60}$ bFGF has been the target of different clinical trials for tissue regeneration, such as periodontal disease and bone fractures. For example, Trafermin, the first recombinant human bFGF product, has been used in clinical practice since June 2001 to treat bed sores and skin ulcers. ${ }^{61}$

This work aims to develop a stable biofunctional polymericcoated AuNP by the LbL assembly of two natural biodegradable polymers with opposite charges, i.e. chitosan and heparin, without the use of synthetic polymers and/or crosslinkers. The adsorption of several layers, instead of one, provides several advantages in the resulting NPs, namely improved stability and robustness as well as a more homogeneous polymeric coating along the NPs surface. Indeed, a greater number of adsorbed layers will increase the inter-layer electrostatic interactions and consequently, the cohesion and mechanical stability of the LbL coating, even in vivo. ${ }^{62}$ The adsorption process of the natural polymers at the $\mathrm{Au}$ surface was firstly followed by quartz crystal microbalance with dissipation (QCM-D) and then by particle size and zeta potential measurements. Nanoparticle tracking analysis (NTA) was also performed to evaluate the NPs size, as well as atomic force microscopy (AFM) and transmission electron microscopy (TEM). Besides giving an indication of the NPs size, the last two characterization techniques are exceptionally important in the investigation of their morphology. Cellular assays were performed with a cell type closely related to the proposed therapeutic indication, namely the chondrocyte cell line ATDC5, which is excellent for finding promising formulations to use in cartilage repair. ${ }^{63}$ Additionally, the local administration of the developed NPs in the joint cavity will lead primarily to high concentrations in the vicinity of chondrocytes. Cellular studies were conducted to evaluate the natural polymer-coated AuNPs cytocompatibility, as well as to assess cell proliferation and protein synthesis. Fourier transform infrared spectroscopy (FTIR) and the Ellman's reagent method ${ }^{64}$ were used to ensure that chitosan was in the external layer of the AuNPs coating, leading to the presence of free amino groups that allow the functionalization of the particles. The antibody anti-bFGF was linked and afterwards it was performed the binding of bFGF to the natural polymer-coated AuNPs surface.

\section{Experimental}

\subsection{Materials and reagents}

Gold(III) $\left(\mathrm{Au}^{3+}\right)$ chloride trihydrate, sodium citrate dehydrate, $N$-(3-dimethylaminopropyl)- $N^{\prime}$-ethylcarbodiimide hydrochloride (EDC), $N$-hydroxysuccinimide (NHS), 5,5'-dithiobis(2-nitrobenzoic acid) or Ellman's reagent (DTNB), 2-iminothiolane (2IT), 4-(dimethylamino)pyridine (DMAP), potassium bromide $(\mathrm{KBr})$, sodium chloride ( $\mathrm{NaCl})$, phosphate buffered saline (PBS) tablets, 
bovine serum albumin (BSA), heparin (grade I-A; $42 \mathrm{kDa}$; degree of sulfation, DS $=1.8-2.4)$ and nitric acid $\left(\mathrm{HNO}_{3}\right)$ were purchased from Sigma-Aldrich. Chitosan $\left(M_{\mathrm{W}}=154 \mathrm{kDa} ; M_{\mathrm{n}}=56 \mathrm{kDa}\right)$ was acquired from Heppe Medical Chitosan $\mathrm{GmbH}$. Hydrochloric acid ( $\mathrm{HCl})$ and sodium hydroxide $(\mathrm{NaOH})$ were purchased from Fisher Scientific. Au standard solution of $1000 \mathrm{~g} \mathrm{~L}^{-1}$ (in $\mathrm{HCl} 20 \%$ ) for ICP determinations was obtained from Panreac. The anti-FGF-2/basic FGF antibody, clone bFM-2 (non-neutralizing antibody), was purchased from Millipore (05-118) and the secondary antibody Alexa Fluor $^{\circledR} 488$ Rabbit Anti-Mouse IgG was purchased from Life Technologies. The recombinant human bFGF was acquired from PeproTech (AF-100-18B). Dulbecco's modified Eagle's medium-F12 (DMEM-F12), antibiotic/antimycotic solution (10000 units $\mathrm{mL}^{-1}$ penicillin $\mathrm{G}$ sodium, $10000 \mu \mathrm{g} \mathrm{\textrm {mL } ^ { - 1 }}$ streptomycin sulfate, and $25 \mu \mathrm{g} \mathrm{mL}^{-1}$ amphotericin B), fetal bovine serum (FBS), trypLE Express and Quant-iT ${ }^{\mathrm{TM}}$ PicoGreen ${ }^{\circledR}$ dsDNA Kit were purchased from Life Technologies. CellTiter 96 AQueous One Solution kit was purchased to Promega, whereas Micro $\mathrm{BCA}^{\mathrm{TM}}$ Protein Assay Kit was purchased from Thermo Scientific. All reagents were used without any further purification.

\subsection{QCM-D measurements}

The build-up of a three bilayer system, composed of two layers of chitosan (polycation) interspersed with one layer of heparin (polyanion), was followed in situ by a QCM-D (E4 instrument, Q-Sense), using Au-coated AT-cut quartz crystals (QSX301, Q-Sense). Polyelectrolyte solutions were freshly prepared at a concentration of $1 \mathrm{mg} \mathrm{mL}{ }^{-1}$ for heparin and $0.5 \mathrm{mg} \mathrm{mL}^{-1}$ for chitosan in $0.15 \mathrm{M} \mathrm{NaCl}$ solution $(\mathrm{pH} \approx 5)$. To obtain the heparin solution, a known amount of heparin was dissolved in $0.15 \mathrm{M} \mathrm{NaCl}$. To prepare the chitosan solution, it was necessary to use a solution of $1 \%$ acetic acid in $0.15 \mathrm{M} \mathrm{NaCl}$. The $\mathrm{pH}$ adjustment of the solutions was performed with $\mathrm{HCl}$ or $\mathrm{NaOH}$ solution.

The QCM-D flow chambers were flushed at a flow rate of

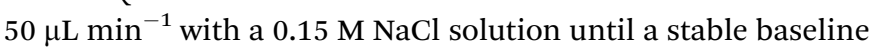
was obtained. The chitosan solution was added to the chambers at the same flow rate and was allowed to adsorb for $15 \mathrm{~min}$. After this first layer adsorption, the sensors were rinsed with the salt solution to remove loosely bound material, for the same period of time. The second layer (heparin) was injected into the chambers and allowed to adsorb for the same period of time, followed by the rinsing step. These adsorption steps were repeated until a chitosan-heparin-chitosan coating was obtained.

QCM-D measurements were performed at several harmonics ( $n=3,5,7,9,11$ and 13); however, only the 3rd, 5th and 7th were considered for further analysis. Thickness calculation was performed on the Q-Tools software ( $\mathrm{v}$ 3.0.6.213), using the Sauerbrey model.

\subsection{AuNPs preparation and coating}

Citrate-capped AuNPs were prepared using the Turkevich method. ${ }^{65}$ Briefly, $0.1 \mathrm{M}$ of sodium citrate was added to reduce the Au salt (1 mM) previously heated to the boiling temperature. The mixture was stirred for at least $3 \mathrm{~h}$ at room temperature (RT).
After washing the AuNPs with water, they were coated using the LbL methodology. The addition of the AuNPs to the polymer solution in $0.15 \mathrm{M} \mathrm{NaCl}(\mathrm{pH} \approx 5)$, prepared as previously mentioned, was placed in an ultrasound bath. The particles were coated with three natural polymeric shells, which were composed sequentially of chitosan then heparin then chitosan. The adsorption of each polymer to the NPs was performed under stirring for $30 \mathrm{~min}$, at RT. Between each adsorption, the suspension was rinsed with water and then placed in the ultrasound bath to disrupt the aggregates.

\subsection{Size distribution and zeta-potential measurements}

Intensity-distribution size was assessed using dynamic light scattering (DLS) at an angle of $173^{\circ}$ and at a wavelength of $633 \mathrm{~nm}$. Zeta-potential values were obtained by laser Doppler electrophoresis. DLS determinations were performed with disposable polystyrene cuvettes. The zeta-potential was measured using a dip cell. The measurements were performed at $25.0 \pm 0.1{ }^{\circ} \mathrm{C}$ using a Zetasizer Nano ZS instrument (Malvern Instruments). The samples were diluted with ultra-pure water, but the dilution factors were different, based on the NPs suspension being analysed, since they presented different initial concentrations.

\subsection{NTA experiments}

NTA experiments allowed the determination of the size and concentration of the NPs suspension, using both light scattering and Brownian motion. Since the NanoSight NS500 instrument includes a charge-coupled device camera it was possible to visualize the NPs under Brownian motion because they scattered the light of the laser beam. Each video was recorded for $60 \mathrm{~s} \mathrm{using}$ the NTA analytical software version 2.3. The analysis was performed at RT for samples that were diluted at least 50 times compared to the tested concentrations in the Zetasizer equipment.

\subsection{AuNPs morphology}

The morphology of AuNPs coated (or not) with natural polymers was assessed using atomic force microscopy (AFM; Dimension Icon, BRUKER) and transmission electron microscopy (TEM; Jeol JEM-1400). AFM analyses (tips Scanasyst Air) were performed in air using dried (at RT) samples deposited on a glass slide. For negative staining TEM, $10 \mu \mathrm{L}$ of samples were mounted on Formvar/carbon film-coated mesh nickel grids (Electron Microscopy Sciences, Hatfield, PA, USA) and left standing for $2 \mathrm{~min}$. The excess liquid was removed with filter paper, $10 \mu \mathrm{L}$ of $1 \%$ uranyl acetate was added to the grids and left standing for $10 \mathrm{~s}$, after which excess liquid was again removed with filter paper. Visualization was carried out at $80 \mathrm{kV}$.

\subsection{FTIR analysis}

FTIR spectra of $\mathrm{KBr}$ pellets of the samples were obtained, at RT using a Shimadzu-IR Prestige 21 spectrometer, as the average of 32 individual scans. The spectral region was from 4000 to $800 \mathrm{~cm}^{-1}$ with a resolution of $2 \mathrm{~cm}^{-1}$, with the background spectra automatically subtracted. 


\subsection{Quantification of free amine groups}

The amount of amino groups present in the natural polymercoated AuNPs was determined using the method described by Tyllianakis et al. ${ }^{64}$ and Monteiro et al. ${ }^{66}$ This method allows the determination of the number of free amino groups by reacting these groups with a solution of equal concentrations of 2IT and DMAP (20 mM) in PBS (0.1 M, pH 8) for $1 \mathrm{~h}$ at $37^{\circ} \mathrm{C}$, giving rise to sulfhydryl groups. After the NPs were washed, they were added to DTNB (0.1 mM) in PBS (0.1 M, pH 7.27), which, in the presence of the sulfhydryl groups, was cleaved to 2-nitro-5thiobenzoate or $\mathrm{TNB}^{-}$. This anion was then reduced to the yellow compound $\mathrm{TNB}^{2-}$ at the considered $\mathrm{pH}$. The reaction was carried out for $1 \mathrm{~h}$ at $37^{\circ} \mathrm{C}$ and after that, the absorbance of the supernatant was determined at $412 \mathrm{~nm}$ in a microplate reader (Synergie HT). Since the stoichiometry is $1: 1$ in both reactions, the determination of the amount of $\mathrm{TNB}^{2-}$, using its molar absorption coefficient value $\left(14150 \mathrm{M}^{-1} \mathrm{~cm}^{-1}\right),{ }^{64}$ allowed the quantification of the amino groups.

\subsection{Biological assays}

2.9.1. Cell culture and seeding. ATDC5, a mouse chondrocyte teratocarcinoma-derived cell line, was supplied by the European Collection of Cell Cultures (ECACC; UK). ATDC5 cells were cultured in DMEM-F12 medium (Life Technologies) supplemented with $10 \%$ heat-inactivated FBS and $1 \%$ antibiotic/ antimycotic solution. The expansion medium was changed every two days and ATDC5 cells were cultured at $37{ }^{\circ} \mathrm{C}$ with $5 \% \mathrm{CO}_{2}$. Confluent chondrocyte cells were detached from the culture flask using TrypLE Express (Life Technologies), counted on a hemocytometer and seeded at a density of 50000 cells per well in a 24 well plate over tissue culture coverslips. NPs at different concentrations were added to the culture medium $24 \mathrm{~h}$ later. Triplicates of each condition were collected 24, 48 and $72 \mathrm{~h}$ after NPs incubation to conduct the following biochemical assays.

2.9.2. Cell morphology. At the predefined time points, the ATDC5 cells were fixed with $2.5 \%$ glutaraldehyde in PBS and dehydrated with increasing concentrations of ethanol. The cells were then sputter-coated with a thin layer $(9-12 \mathrm{~nm})$ of $\mathrm{Au}$ /palladium (Cressington $208 \mathrm{HR}$ ) and analysed using scanning electron microscopy (SEM; NanoSEM, Nova 200). Micrographs were recorded at $5.00 \mathrm{kV}$ with magnifications ranging from 200 to $10000 \times$.

2.9.3. Cell Viability. The viability of ATDC5 cells was determined by using the CellTiter 96 AQueous One Solution kit (Promega). At defined times points, a mixture of culture medium and MTS reagent (5:1 ratio) was added to each well and left to incubate for $3 \mathrm{~h}$ at $37{ }^{\circ} \mathrm{C}$ in a humidified $5 \% \mathrm{CO}_{2}$ atmosphere. All investigations were performed in triplicate. Thereafter, the absorbance of the MTS reaction medium from each sample was read in triplicate at $490 \mathrm{~nm}$ (Synergy HT, Bio-TEK).

2.9.4. DNA quantification. DNA quantification was assessed using Quant-iT ${ }^{\mathrm{TM}}$ PicoGreen ${ }^{\circledR}$ dsDNA Kit (Life Technologies), according to the manufacturer's instructions. The specimens were collected and $1 \mathrm{~mL}$ of sterile distilled water was added and stored at $-80{ }^{\circ} \mathrm{C}$ until further analysis. Prior to quantification, the samples were defrosted and sonicated for $15 \mathrm{~min}$. To interpolate the DNA values for each sample, a set of standards was prepared with concentrations ranging from 0 to $1.5 \mu \mathrm{g} \mathrm{mL} L^{-1}$. The fluorescence of each sample was measured on an opaque 96-well plate using a microplate reader (Synergie HT, Bio-Tek) and an excitation wavelength of $485 / 20 \mathrm{~nm}$ and an emission wavelength of $528 / 20 \mathrm{~nm}$.

2.9.5. Total protein synthesis quantification. Total protein synthesis quantification was performed using the Micro $\mathrm{BCA}^{\mathrm{TM}}$ Protein Assay Kit (Thermo Scientific), according to the manufacturer's instructions. A standard curve was prepared using concentrations ranging from 0 to $200 \mu \mathrm{g} \mathrm{mL} \mathrm{m}^{-1}$. The absorbance of each sample was measured at $562 \mathrm{~nm}$ using a microplate reader (Synergie HT, Bio-Tek).

\subsection{Anti-bFGF immobilization and its quantification at the NPs surface}

The anti-bFGF antibody was immobilized on the natural polymer-coated AuNPs after its activation using the optimized ratio of EDC:NHS $(50 \mathrm{mM}: 200 \mathrm{mM}){ }^{67}$ Before putting the activated antibody in contact with the natural polymer-coated AuNPs, it was dialyzed (Micro Float-A-Lyzer ${ }^{\circledR}$, MWCO: $3.5-5$ kDa) to remove the excess EDC:NHS. The natural polymer-coated AuNPs were incubated overnight at $4{ }^{\circ} \mathrm{C}$ with an excess of the activated anti-bFGF. Subsequently, the functionalized AuNPs were washed with water and then they were immersed in a solution of BSA (3\%) for $1 \mathrm{~h}$ at RT. After blocking nonspecific sites, the secondary antibody, Alexa Fluor ${ }^{\circledR}$, was added to the NPs pellet, and after $1 \mathrm{~h}$ at RT, the fluorescence intensity of the supernatant (unbound secondary antibody) was measured in a microplate reader (Synergy HT, Bio-TEK), setting the excitation wavelength at $485 \mathrm{~nm}$ and the emission wavelength at $530 \mathrm{~nm}$.

\subsection{Quantification of bFGF binding by the functionalized AuNPs}

To obtain the natural polymer-coated AuNPs bound to bFGF, equal amounts of bFGF were added to increasing concentrations of NPs. After overnight incubation at $4{ }^{\circ} \mathrm{C}$, the unbound GF was quantified using the Quantikine ${ }^{\circledR}$ Human FGF basic ELISA Kit (R\&D Systems). The assay was performed according to the manufacturer's instructions. After addition of the stop solution to each well, the absorbance values obtained at $450 \mathrm{~nm}$ were corrected by subtracting the data acquired at $540 \mathrm{~nm}$ in a microplate reader (Synergy HT, Bio-TEK).

\subsection{Au quantification by inductively coupled plasma optical emission spectrometry (ICP-OES)}

$\mathrm{Au}$ concentration was determined via ICP-OES (JY 2000 2, HORIBA JOBIN YVON, Inc.), at $242.795 \mathrm{~nm}$, after the dissolution of the AuNPs with $2.5 \%$ of $\mathrm{HNO}_{3}$ and $5 \%$ of $\mathrm{HCl}$. All measurements were carried out in triplicate.

\subsection{Statistical analysis}

Physicochemical characterization data were reported as the average \pm standard deviation. Statistical analysis of biological 
assays was conducted by using the IBM SPSS software (version 23; SPSS Inc.). The Shapiro-Wilk test was applied to test the assumption of normality. $p$ values lower than 0.01 were considered statistically significant. Non-parametric analysis of the data was done using the Kruskal-Wallis test, followed by Tukey's HSD test.

\section{Results}

\subsection{Monitoring of the polymeric layer construction by QCM-D measurements}

The frequency and dissipation signal changes are shown in Fig. 1A; the shifts are higher for the adsorption of chitosan (1st and 3rd layers) than for heparin. A similar trend was observed for the polyelectrolyte layer behaviour concerning the $\Delta D / \Delta f$ values either in the presence of chitosan or heparin (Fig. 1B). From the analysis of Fig. 1B, the values of $\Delta D / \Delta f$ were $<0.4 \times 10^{-6}$ (with the exception of the chitosan 1st layer at $n=7$ ), and therefore the multilayer film can be considered rigid, and the Sauerbrey model can be used to predict the thickness of each deposited layer. ${ }^{68}$ The thickness of the multilayer film reached approximately $5.5 \mathrm{~nm}$ (Fig. S1, ESI $\dagger$ ), with a larger contribution from the chitosan layers (a total of approximately $5 \mathrm{~nm}$ for the 2 layers) than the heparin layer (approximately $0.5 \mathrm{~nm}$ for 1 layer). The mass of each adsorbed layer (polymer plus coupled water) was also quantified, presenting the first and last layers of chitosan $\approx 2.41$ and
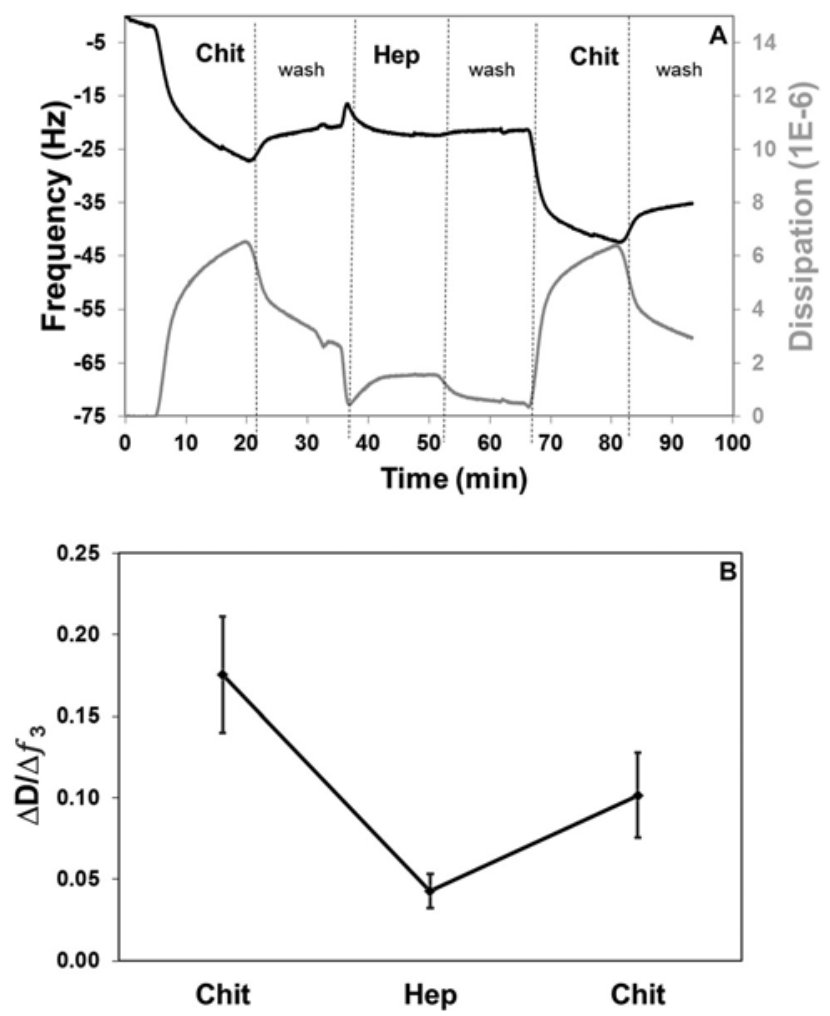

Fig. 1 QCM-D data for the build-up of the three layers. Frequency and dissipation shifts recorded in real-time (A), and $\Delta D / \Delta f$ plots for the assembly of (Chit-Hep-Chit) using the 3rd overtone (B).
$1.05 \mu \mathrm{g} \mathrm{cm}{ }^{-2}$, respectively, and for heparin the value obtained was $\approx 0.15 \mu \mathrm{g} \mathrm{cm}{ }^{-2}$.

\subsection{AuNP characterization}

The size, polydispersity index (PDI) and zeta potential of the AuNPs coated (or not) with three natural polymer layers are presented in Table 1 . The citrate-coated AuNPs present a negative charge, which changes to positive with the adsorption of chitosan (1st and 3rd layer). The adsorption of heparin (2nd layer) to chitosan led to the appearance of NPs presenting an electrical charge of the same signal $(-35.9 \pm 3.7 \mathrm{mV})$ for the uncoated AuNPs. The size of the NPs increased, as expected, with the adsorption of the polymer layers. Additionally, from Table 1 it is also possible to conclude that the sequential adsorption of the natural polymers leads to a more homogeneous population of NPs in terms of size (the PDI of the natural polymers-coated AuNPs is lower than AuNPs).

AFM and TEM micrographs (Fig. 2) show that the produced particles present a spherical shape. Moreover, TEM images (Fig. 2A2) allow visualization of the polymeric coating around the AuNPs. These techniques also permit the determination of their size, which is not in agreement with the DLS data. Indeed, the size of the natural polymer-coated AuNPs obtained by AFM was between 25 and $35 \mathrm{~nm}$, and the size obtained by TEM was between 22 and $35 \mathrm{~nm}$.

The size of the natural polymer-coated AuNPs was further analysed by NTA. Besides the measurement of this physical property, this method allowed the real-time visualization of the particles (Video S1, ESI $\dagger$ ) and the determination of their concentration. The sizes of the natural polymer-coated AuNPs obtained by this technique (Fig. 3) were in agreement with the DLS data.

The positive surface charge of the NPs confirmed the presence of chitosan in the last layer, which was also corroborated by FTIR (Fig. 4). Finally, since chitosan has a greater number of amino groups in the structure, which are not present in heparin, their quantification (Table 2) also confirms that the last layer is composed of chitosan.

\subsection{Cellular assays}

The morphology of chondrocyte cells cultured in the presence of increasing concentrations of AuNPs or natural polymercoated AuNPs is presented in Fig. 5. The cells maintained their morphology even after $72 \mathrm{~h}$ of contact with NPs. Additionally, MTS assay results (Fig. 6) showed that chondrocyte cells

Table 1 Zeta potential, diameter and PDI values obtained by DLS and laser Doppler electrophoresis, respectively, for AuNPs coated (or not) with three layers of natural polymers, namely chitosan (Chit) heparin (Hep) and chitosan (Chit)

\begin{tabular}{llcl}
\hline NPs composition & $\begin{array}{l}\text { Zeta potential } \\
(\mathrm{mV})\end{array}$ & Size $(\mathrm{nm})$ & PDI \\
\hline AuNPs & $-22.7 \pm 5.6$ & $22.5 \pm 1.6$ & $0.557 \pm 0.085$ \\
AuNPs + Chit + & $+29.3 \pm 5.2$ & $164.2 \pm 11.1$ & $0.226 \pm 0.029$
\end{tabular}

Hep + Chit 


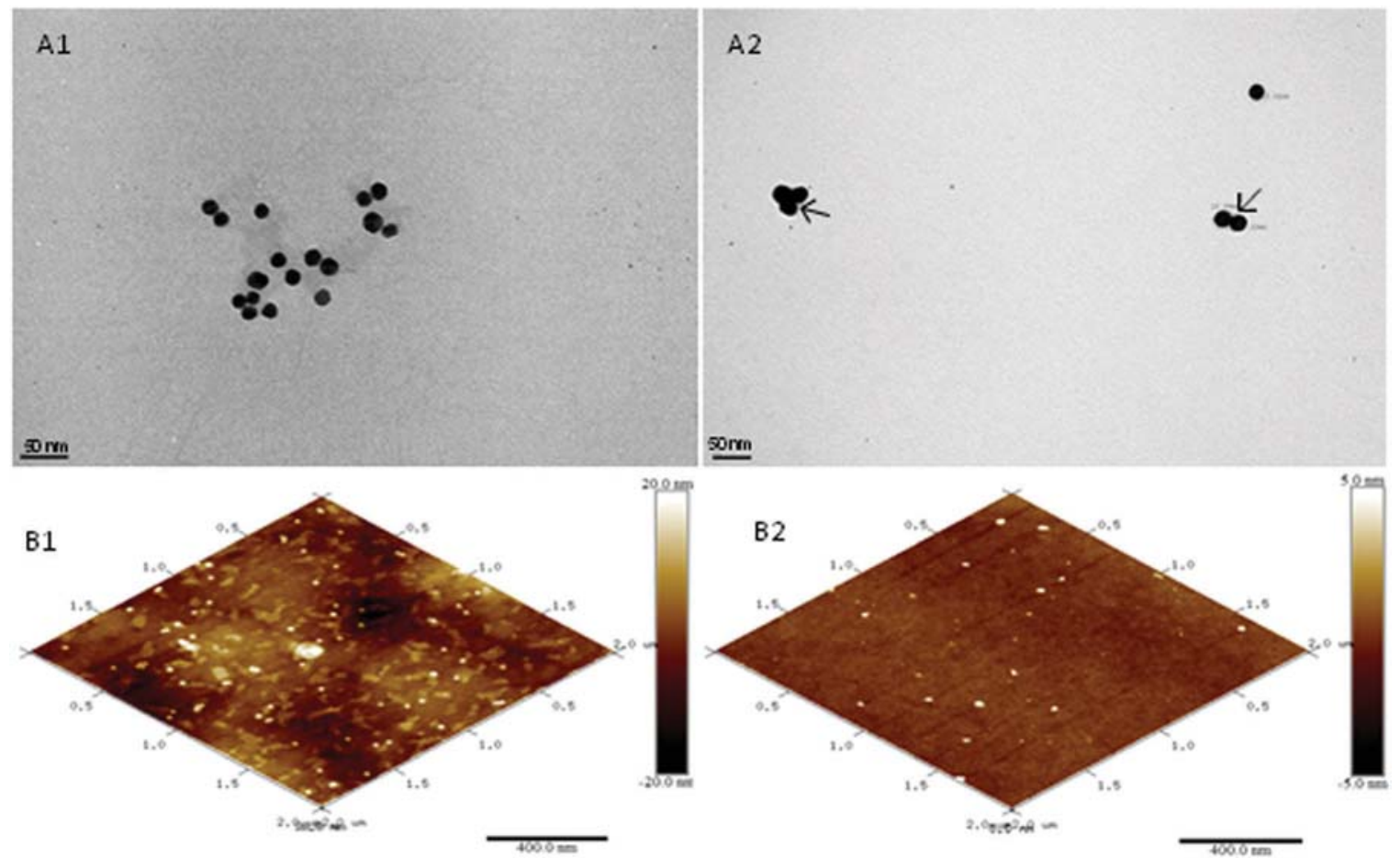

Fig. 2 Representative TEM (A) or AFM (B) images of AuNPs without (1) or with three layers of natural polymers (2). The arrows ( $\swarrow$ ) indicate the coating surrounding the AuNPs.

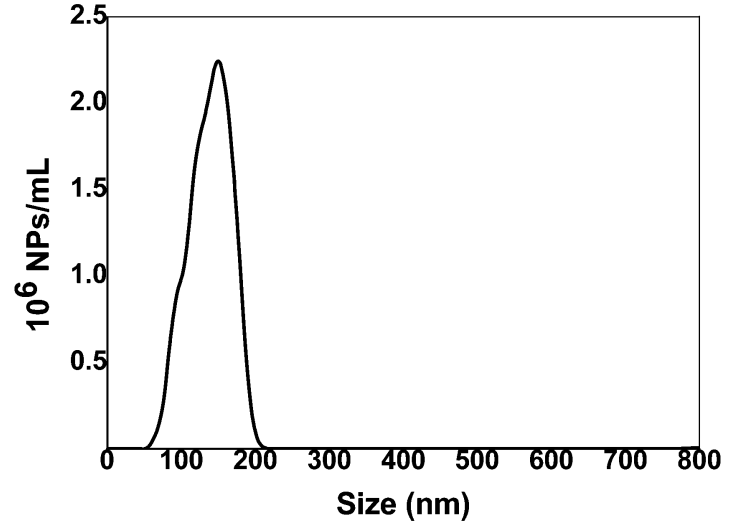

Fig. 3 NTA analysis of the natural polymer-coated AuNPs size distribution.

remained viable throughout the experiment and no significant differences, except the $\mathrm{Au}$ concentration of $160 \mu \mathrm{M}$ in the uncoated AuNPs at $48 \mathrm{~h}$, were observed between the standard culture conditions ( $0 \mu \mathrm{M}$ of $\mathrm{Au})$ and the NPs at different concentrations, for the different time points. As expected, the presence of natural polymers enhanced the ATDC5 cell viability.

The cell proliferation assay (Fig. 7) clearly demonstrated that the NPs presented significant inhibition of cell proliferation only for concentrations above $80 \mu \mathrm{M}$ (Kruskal-Wallis test, Tukey's HSD test, $p<0.01$ ). Furthermore, suspensions of AuNPs having a Au concentration of 10 and $20 \mu \mathrm{M}$ generally displayed a significantly higher cell proliferation than all other

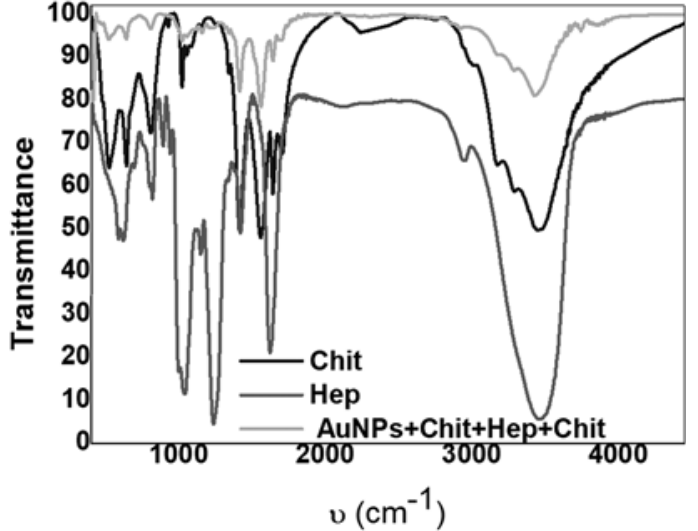

Fig. 4 FTIR spectra of chitosan (Chit), heparin (Hep) and AuNPs after coating with two layers of Chit interspersed with one layer of Hep.

Table 2 Concentration of amino $\left(\mathrm{NH}_{2}\right)$ groups in the presence of increasing concentrations of natural polymer-coated AuNPs (measured in terms of the Au atom concentration using ICP-OES)

\begin{tabular}{ll}
\hline$[\mathrm{Au}]\left(\mu \mathrm{g} \mathrm{mL} \mathrm{mL}^{-1}\right)$ & {$\left[\mathrm{NH}_{2}\right](\mu \mathrm{M})$} \\
\hline 500 & $18.0 \pm 3.4$ \\
1000 & $55.2 \pm 12.9$ \\
2000 & $132.0 \pm 22.5$ \\
4000 & $272.2 \pm 24.4$
\end{tabular}

concentrations of NPs (Kruskal-Wallis test, Tukey's HSD test, $p<0.01$ ), despite their coated counterparts. Chondrocyte cells were also able to increasingly synthesize proteins throughout 


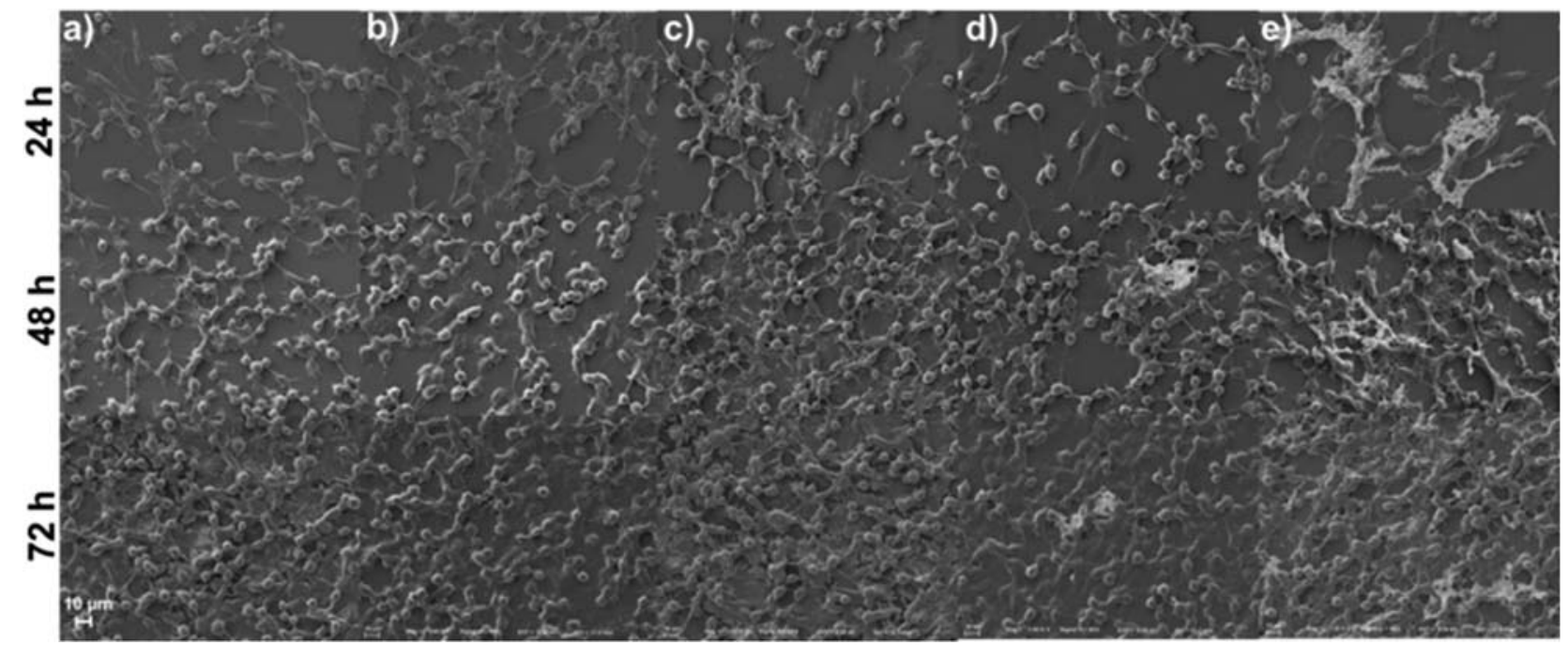

Fig. 5 SEM micrographs ( $\times 1000$ magnification) of chondrocyte cells cultured in the absence (a) or in the presence of increasing concentrations of AuNPs (b: 10 and c: $160 \mu \mathrm{M}$ of Au atoms) or AuNPs covered with three polymeric layers (d: 10 and e: $160 \mu \mathrm{M}$ of Au atoms), after 24,48 and $72 \mathrm{~h}$. The Au concentration was determined by ICP-OES

the experiment, although no significant differences were observed between the standard culture conditions (i.e. cultured in the absence of $\mathrm{Au}$ ) and the NPs at different concentrations, for the different time points (Fig. 8). Interestingly, and following the trend of the viability results, the presence of natural polymers induced ATDC5 cells to synthesize more protein than the AuNPs concentrations of their counterparts.

\subsection{AuNPs functionalization}

The covalent coupling of the anti-bFGF antibody was determined by an indirect method, through the measurement of the fluorescence of the unbound secondary antibody. The difference between the fluorescence obtained for the total amount of the secondary antibody used and that acquired in the presence of different concentrations of NPs allowed the determination of the quantity that was retained by the particles (Fig. 9). Considering the molecular weight of the secondary antibody, it was possible to obtain its number of moles and consequently, the quantity of the anti-bFGF antibody presented at the NPs surface (Table S1, ESI $\dagger$ ). Afterwards of removing the unbound anti-bFGF antibody, equal amounts of bFGF were added to different concentrations of NPs suspensions. As can be observed in Table 3, the functionalized AuNPs were able to bind a higher percentage of bFGF; the suspension with $1000 \mu \mathrm{g} \mathrm{mL} \mathrm{m}^{-1}$ of Au retained virtually almost all the GF added.

The size of the natural polymer-coated AuNPs with immobilized anti-bFGF linked to bFGF was $176.6 \pm 12.5 \mathrm{~nm}$, with a PDI of $0.243 \pm 0.017$ and a negative surface charge $(-26.6 \pm$ $4.0 \mathrm{mV})$.

\section{Discussion}

This work aimed to develop functionalized AuNPs with the potential for use in a theranostic approach related to the regulation of different cellular processes. Although immobilized antibodies are usually used to direct NPs to a defined cell or tissue, in the current study, they were used to specifically bind a relevant bioactive factor. It was intended that the captured agent would conduct the desired therapeutic effect after administration. To demonstrate the feasibility of the developed AuNPs for used in a biomedical approach, NPs were designed to immobilize a defined antibody that allows the specific binding of bFGF, which has multiple biological functions. However, instead of being incorporated into the polymeric matrix, bFGF was linked to a specific antibody. Since the anti-bFGF antibody used in this work is not a neutralizing antibody, the GF can exert its key roles in a wide range of biological functions. ${ }^{51}$

The construction of the LbL polymeric system was first followed and analysed by QCM-D. The assemblies between the positively charged chitosan and the negatively charged heparin, using QCM-D equipment, have been the focus of several studies in planar surfaces, and their multilayer construction (up to 10 layers) is described in literature. ${ }^{69-71}$ Herein, we focused on the analysis of the adsorption of three layers (two layers of chitosan interspersed with one layer of heparin), following its construction in real-time by monitoring the frequency $(\Delta f)$ and dissipation $(\Delta D)$ shifts, for the 3rd, 5th and 7th overtones. The adsorption of each layer involves three major steps: ${ }^{72}$ (1) rapid adsorption of the polyelectrolyte; (2) polyelectrolyte saturation onto the Au quartz crystal surface and reorganization of the layers; (3) the washing step, in which the loosely bound material is removed (Fig. 1A). The adsorption of chitosan and/or heparin led to a change in the quartz sensor oscillation, with its resonance frequency being lower. The shift in resonance frequency is related to the mass adsorbed on the quartz sensor, not only by the material itself, but also by the coupled water. The energy dissipation changes represent the viscoelastic properties of the layers, since the higher the $\Delta D$, 

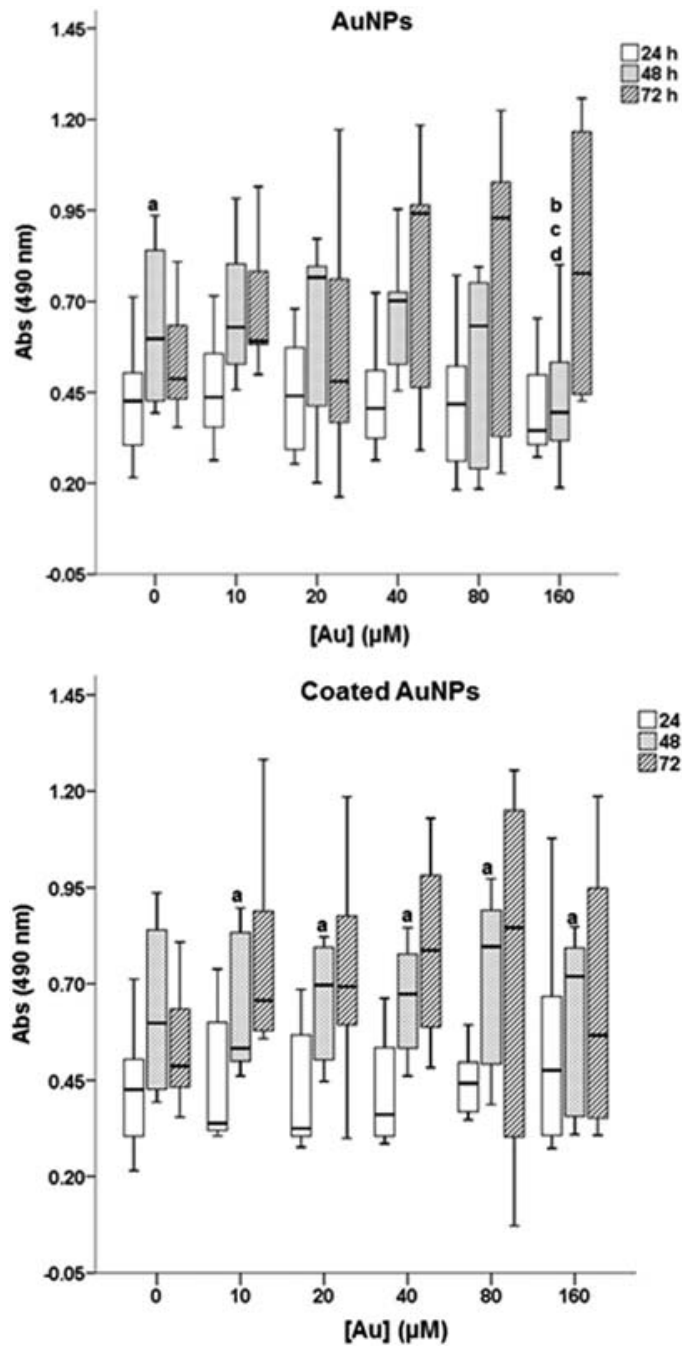

Fig. 6 Box plots of cell viability when cultured in the absence (cells cultured only with culture medium) or in the presence of increasing concentrations $(10,20,40,80$ and $160 \mu \mathrm{M}$ of Au atoms determined by ICP-OES) of AuNPs or AuNPs covered with three polymeric layers after 24, 48 and 72 h. Data were analysed non-parametrically using the KruskalWallis test, followed by Tukey's HSD test. Statistically significant differences are indicated as follows: a denotes significant differences compared to $160 \mu \mathrm{M}$ of $\mathrm{Au}$ in AuNPs, $\mathrm{b}$ denotes significant differences compared to $10 \mu \mathrm{M}$ of $\mathrm{Au}$ in AuNPs, $\mathrm{c}$ denotes significant differences compared to $20 \mu \mathrm{M}$ of $\mathrm{Au}$ in AuNPs, and d denotes significant differences compared to $40 \mu \mathrm{M}$ of $\mathrm{Au}$ in AuNPs.

the softer and/or more hydrated is the polymeric system; on the other hand, the lower the $\Delta D$, the more rigid and compact is the film. Chitosan and heparin had opposite behaviours regarding the frequency and dissipation signal changes (Fig. 1A). The adsorption of chitosan (1st and 3rd layers) presented higher frequency and dissipation shifts compared to heparin (2nd layer). These higher values of frequency and dissipation suggest that the mass of chitosan is sensed, as well as the water entrapped in its structure, leading to an increase in $\Delta f$ and $\Delta D$ values. $^{73}$ Therefore, while the adsorption of the chitosan layers is accompanied by a large dissipation shift, the heparin layer has a very small $\Delta D$ shift, forming a less hydrated layer. To confirm the water content
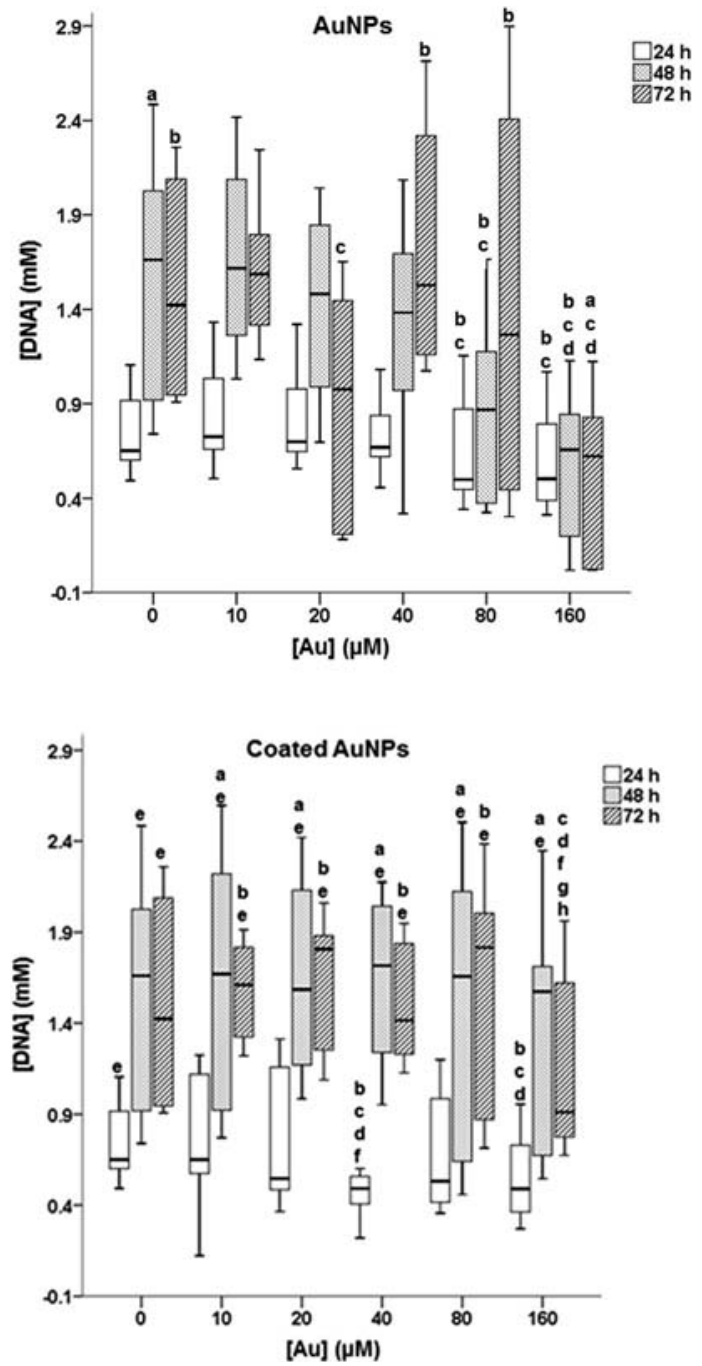

Fig. 7 Box plots of ATDC 5 cell proliferation in the absence (cells cultured only with culture medium) or in contact with increasing concentrations $(10,20,40,80$ and $160 \mu \mathrm{M}$ of Au atoms determined by ICP-OES) of AuNPs or AuNPs covered with three polymeric layers after 24, 48 and $72 \mathrm{~h}$. Data were analysed by the non-parametric Kruskal-Wallis test, followed by Tukey's HSD test. Statistically significant differences are indicated as follows: a denotes significant differences compared to $80 \mu \mathrm{M}$ of $\mathrm{Au}$ in AuNPs, b denotes significant differences compared to $20 \mu \mathrm{M}$ of $\mathrm{Au}$ in AuNPs, c denotes significant differences compared to $10 \mu \mathrm{M}$ of $\mathrm{Au}$ in AuNPs, d denotes significant differences compared to $40 \mu \mathrm{M}$ of $\mathrm{Au}$ in AuNPs, e denotes significant differences compared to $160 \mu \mathrm{M}$ of $\mathrm{Au}$ in AuNPs, $f$ denotes significant differences compared to $10 \mu \mathrm{M}$ of $\mathrm{Au}$ in coated AuNPs, g denotes significant differences compared to $20 \mu \mathrm{M}$ of $\mathrm{Au}$ in coated AuNPs and $\mathrm{h}$ denotes significant differences compared to $80 \mu \mathrm{M}$ of $\mathrm{Au}$ in coated AuNPs.

hypothesis (observed on QCM-D signals), $\Delta D / \Delta f$ was plotted as a function of the deposited layer (Fig. 1B) in order to evaluate the dissipation per adsorbed mass. This normalization of the dissipation by the adsorbed mass can better detail the hydration state of the adsorbed layers. The higher values of the normalized dissipation $(\Delta D / \Delta f)$ obtained by chitosan indicate that this polycation produces more hydrated layers when compared with heparin. In fact, heparin is a highly sulphated polyelectrolyte and because 

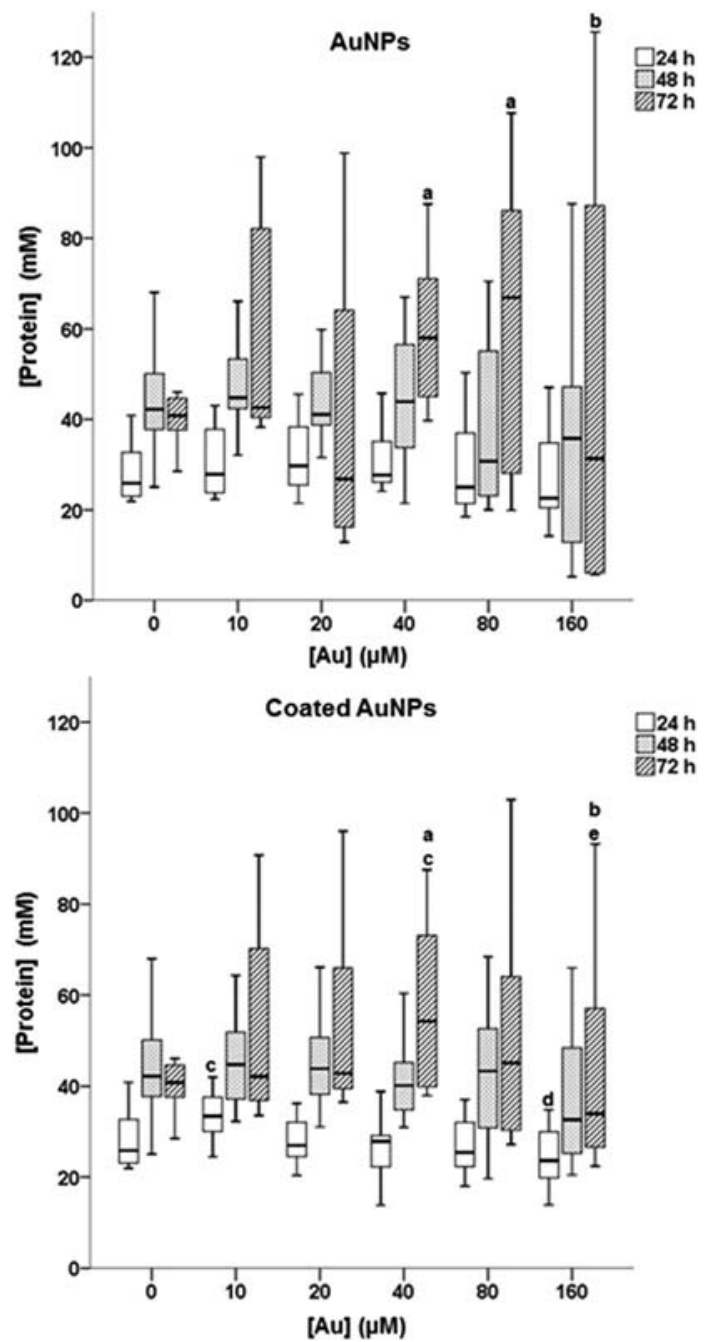

Fig. 8 Box plots of total protein synthesis by ATDC5 cells cultured in the absence (cells cultured only with culture medium) or in the presence of increasing concentrations $(10,20,40,80$ and $160 \mu \mathrm{M}$ of $\mathrm{Au}$ atoms determined by ICP-OES) of AuNPs or AuNPs covered with three polymeric layers after 24, 48 and $72 \mathrm{~h}$. Data were analysed by the non-parametric Kruskal-Wallis test, followed by Tukey's HSD test. Statistically significant differences are indicated as follows: a denotes significant differences compared to $20 \mu \mathrm{M}$ of $\mathrm{Au}$ in AuNPs, b denotes significant differences compared to $40 \mu \mathrm{M}$ of Au in AuNPs, c denotes significant differences compared to $160 \mu \mathrm{M}$ of $\mathrm{Au}$ in AuNPs, d denotes significant differences compared to $10 \mu \mathrm{M}$ of $\mathrm{Au}$ in coated AuNPs and e denotes significant differences compared to $40 \mu \mathrm{M}$ of $\mathrm{Au}$ in coated AuNPs.

of the negative charge of $\mathrm{SO}_{3}{ }^{-}$, which is spread over three oxygens, it is considered a weakly hydrated anion. ${ }^{74}$ It is important to note that despite the film being considered as "quasi-rigid", the water content, particularly on the chitosan layers, also contributes to the thickness estimation. In this sense, the thicker chitosan layers might be associated with the entrapment of water, leading to a thicker coating. After the QCM-D analyses, the assembly of the natural polymers was monitored by zetasizer measurements. The change observed in the surface charge of the NPs constitutes a good parameter to evaluate the adsorption of the polymers. As chitosan was solubilized in $0.15 \mathrm{M} \mathrm{NaCl}\left(0.5 \mathrm{mg} \mathrm{mL}{ }^{-1}, \mathrm{pH} 5\right)$,

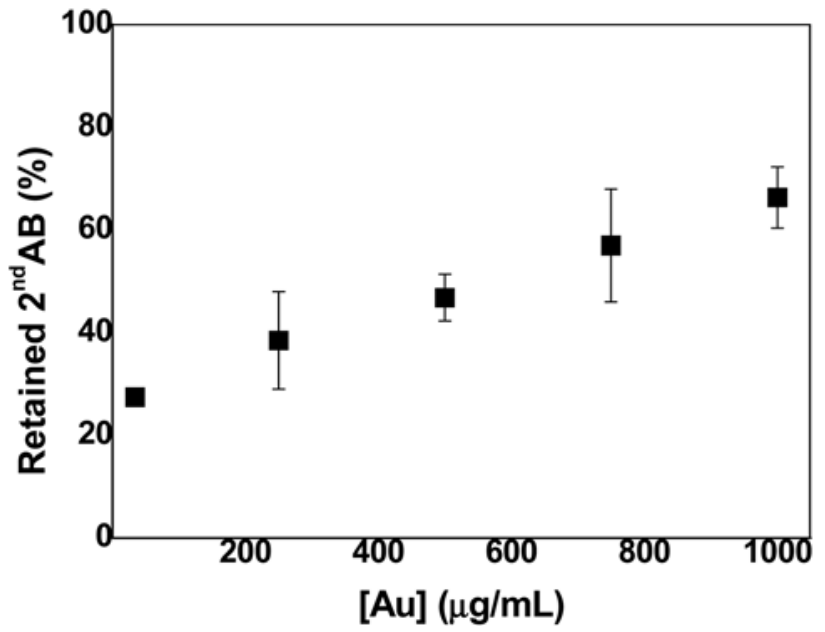

Fig. 9 Percentage (\%) of the secondary antibody (2nd Ab) linked to the anti-bFGF antibody immobilized at the surface of natural polymer-coated NPs, in the presence of increasing concentrations of AuNPs. Au concentration was determined by ICP-OES.

Table 3 Percentage of recombinant human bFGF bound to the antibody immobilized at the natural polymer-coated AuNPs surface

\begin{tabular}{ll}
\hline$[\mathrm{Au}]\left(\mu \mathrm{g} \mathrm{mL}^{-1}\right)$ & bFGF bound $(\%)$ \\
\hline 250 & $83.2 \pm 5.9$ \\
500 & $93.8 \pm 4.4$ \\
750 & $96.0 \pm 3.8$ \\
1000 & $99.6 \pm 0.3$
\end{tabular}

presenting a positive charge $(+25.7 \pm 0.2 \mathrm{mV})$, it was expected that its adsorption to the NPs surface would confer a positive charge. The opposite was observed for heparin since it had a negative charge $(-19.9 \pm 1.6 \mathrm{mV})$ when dissolved in $0.15 \mathrm{M} \mathrm{NaCl}$ $\left(1 \mathrm{mg} \mathrm{mL}{ }^{-1}\right)$. The zeta-potential variation with the adsorption of each polymer layer was accompanied by an increase in the NPs size and homogeneity (lower PDI). However, the diameter of the natural polymer-coated AuNPs obtained by DLS (Table 1) was very different from that obtained by AFM and TEM (Fig. 2). The differences observed between the DLS and the microscopic techniques may be explained by the fact that in the first technique the analysis was performed in an aqueous suspension and in the other methodologies the samples were analysed in the dry state. The data obtained by DLS are not directly comparable with AFM and TEM results, nor with the data gathered by QCM-D measurements. DLS provides an indication of the hydrodynamic diameter of the particles by means of a sphere with the same translational diffusion coefficient as the particles under study. This type of analysis also assumes a hydration layer surrounding the particle that is not accounted for in the QCM-D analysis, thus leading to the differences in the thickness of each layer obtained by QCM-D and DLS, qualitatively. However, the QCM-D and DLS data are consistent, since the adsorption of chitosan led to thicker layers than the ones obtained for heparin (data not shown).

NTA was used to further analyse the size of the natural polymer-coated AuNPs. In this technique, the size was measured using the same principle of the Zetasizer equipment 
(light scattering) and it was not surprising that the data acquired from both analyses were in agreement (Fig. 3 and Table 1). Additionally, since NTA allows the real-time visualization of the particles (Video S1, ESI $\dagger$ ), it is possible to conclude that the increase in NPs size was not due to their aggregation. The NTA analyses clearly showed that the natural polymer-coated AuNPs were spherical and were separate entities. Indeed, the coating of the AuNPs with polymers can lead to a significant increase in their size. Labala et al., ${ }^{75}$ for example, reported that the size of the AuNPs increased from $26.6 \pm 2.6 \mathrm{~nm}$ to $98.5 \pm$ $4.3 \mathrm{~nm}$ after being coated with 3 layers of synthetic polymers. Additionally, similar behaviour of the PDI values was observed, since a more homogeneous population was obtained with an increase in the number of layers. The observed increased in size can be higher if natural polymers are used; synthetic polymers are in general less hydratable than natural polymers. For instance, the coating of silica NPs with poly-L-lysine and hyaluronic acid led to an increase in their size to about $327 \mathrm{~nm}$, with the natural polymer contributing to $\approx 91 \%$ of that increment. ${ }^{76}$ Additionally, it was demonstrated that coating AuNPs of size $24.0 \pm 6.2 \mathrm{~nm}$ with glycol chitosan increased their diameter to $99.4 \pm 16.8 \mathrm{~nm}^{77}$ A similar result was obtained by Bhumkar et al. using chitosan. ${ }^{78}$ As in NTA, it was necessary to dilute the NPs suspension to a high degree, it was also possible to conclude that the electrostatic interactions between the AuNPs and the natural polymers were strong enough to avoid their decomplexation. ${ }^{79}$ Indeed, in ionically crosslinked NPs, the electrostatic forces should promote the required stability until NPs accomplished their biological activity. ${ }^{77,80-88}$

The biological assays, through the SEM images of the chondrocyte cells cultured in the presence of increasing concentrations of AuNPs coated (or not) with natural polymers (Fig. 5), demonstrated that NPs interact with cells without a negative effect on their density, shape and volume (without shrinkage). However, in Fig. 5e, a light gray structure is observed (which was not observed in the control and in the other samples with AuNPs), which could be due to the presence of the natural polymer-coated AuNPs; it was observed at higher magnification (the data are not shown) that the light gray structure does not correspond to cells. Additionally, the light gray structure is more visible in the first image (Fig. 5e), most likely due to the presence of a smaller number of cells, a shorter incubation time and a higher concentration of NPs, when compared with Fig. 5d. Cells remained viable throughout the experiment (Fig. 6). Furthermore, the ATDC5 cells presented a higher viability when cultured in the presence of natural polymercoated AuNPs, which was expected since AuNPs are usually covered with polymers to impart biocompatibility. ${ }^{16}$ A similar trend was obtained for cellular proliferation and protein synthesis, despite the statistical significance. This is in agreement with previous studies that also showed that, for example, citratecapped AuNPs of $18 \mathrm{~nm}$ are not toxic to the K562 leukemia cell line at $\mathrm{Au}$ concentrations up to $250 \mu \mathrm{M}$. $^{89}$ Additionally, it was demonstrated that AuNPs presenting three different sizes (18, 35 and $65 \mathrm{~nm}$ ) and coated or not with five different polymers (PEG, glucosamine, hydroxypropylamine, ethanediamine, and taurine) neither induced cytotoxicity nor impaired the morphology of primary human dermal microvascular endothelial cells until the concentration of $250 \mu \mathrm{g} \mathrm{mL}{ }^{-1} \cdot{ }^{90}$ Moreover, natural-polymer coated AuNPs present lower toxicity than synthetic polymer-coated AuNPs. ${ }^{88}$ Finally, AuNPs covered with chitosan did not present significant cytotoxicity against mammalian somatic and tumoral cells lines (an immortal human keratinocyte and human lung adenocarcinoma epithelial cell lines) in the concentration range of $125 \mu \mathrm{M}$ to $1.25 \mathrm{mM}$ and 7.1 to $714.4 \mu \mathrm{M}$, respectively. ${ }^{91}$

The immobilization of the anti-bFGF antibody on the surface of the natural polymer-coated AuNPs was performed using the NPs amino groups available from the chitosan layer (heparin does not contain this functional group) and EDC/NHS solution. The presence of chitosan/amino groups in the last layer was confirmed by the positive surface charge of the NPs by FTIR analyses (Fig. 4) and by the Ellman's reagent method (Table 2). The immobilization of the antibody was followed by its linking to bFGF, which led to an increase in NPs diameter of approximately $7 \%$ in relation to NPs without functionalization. Considering the size of anti-bFGF (155 amino acids; $17.5 \mathrm{kDa}$ ) and bFGF (154 amino acids; $17.2 \mathrm{kDa}$ with a radius of $1.45 \mathrm{~nm}),{ }^{47}$ it was expected that the overall size of NPs did not suffer a remarkable increase. The negative charge of the final system is due to the fact that either the antibody or the bFGF presents a negative zeta potential in water (for example, $-12.46 \pm 4.4 \mathrm{mV}$ for $0.0125 \mathrm{mg} \mathrm{mL}^{-1}$ of anti-bFGF antibody and $-21.8 \pm 1.68 \mathrm{mV}$ for $0.167 \mathrm{mg} \mathrm{mL}^{-1}$ of bFGF). In vitro studies demonstrated that a low dose $\left(3 \mathrm{ng} \mathrm{mL^{-1 }}\right)$ of this protein has the ability to stimulate the proliferation and expression of extracellular matrix proteins and cytoskeletal constituents. ${ }^{54}$ Consequently, Hankemeier et al. proposed its use in the engineering of bioartificial tendons and ligaments. The bFGF concentration reached in the developed NPs (until a maximum of $60.3 \pm$ $24.5 \mathrm{ng} \mathrm{mL}^{-1}$ ), without a negative effect in cell behaviour, demonstrates the potential application of this nanoplatform in the medical area since the bFGF linked to the antibody retains its biological activity. ${ }^{92}$ This is extremely important since this GF should be administered in a carrier to enhance its half-life and to allow the maintenance of its bioactivity.

\section{Conclusions}

From all the obtained results, we conclude that AuNPs coated only with natural polymers were successfully produced and are capable of immobilizing an antibody, which allows the specific binding of bFGF. The natural polymer-coated AuNPs demonstrated enhanced cytocompatibility compared to the AuNPs. Moreover, they allowed chondrocyte cells to grow and proliferate throughout the course of the experiment. The strategy and the devices developed in this work allow for their being tailored to the monitoring and treatment of different diseases, when efficiently functionalized for the proposed objective. In this sense, the developed AuNPs are a promising tool to use as nanotheranostic platforms for different conditions, boosting healing processes.

\section{Conflicts of interest}

There are no conflicts to declare. 


\section{Acknowledgements}

The authors acknowledge QREN (project "RL2-SCN-NORTE-070124-FEDER-000018" co-financed by the North Portugal Regional Operational Programme (ON.2, O Novo Norte) under the NSRF through the ERDF), Portuguese Foundation for Science and Technology (project PTDC/CTM-BIO/4388/2014-SPARTAN) and European Research Council grant agreement ERC-2012ADG-20120216-321266 - project ComplexiTE for financing this research work. Authors would also like to thank the Portuguese Foundation for Science and Technology for the Post-Doc grant of Marta Alves da Silva (SFRH/BPD/73322/2010, financed by POPH QREN - Tipologia 4.1 - Advanced Formation, co-financed by Fundo Social Europeu and MEC national funds).

\section{Notes and references}

1 A. C. Anselmo and S. Mitragotri, Bioeng. Transl. Med., 2016, 1, 10-29.

2 J. V. Jokerst, T. Lobovkina, R. N. Zare and S. S. Gambhir, Nanomedicine, 2011, 6, 715-728.

3 L. Y. Rizzo, B. Theek, G. Storm, F. Kiessling and T. Lammers, Curr. Opin. Biotechnol., 2013, 24, 1159-1166.

4 J. A. Barreto, W. O’Malley, M. Kubeil, B. Graham, H. Stephan and L. Spiccia, Adv. Mater., 2011, 23, H18-H40.

5 B. Sumer and J. Gao, Nanomedicine, 2008, 3, 137-140.

6 C. Zhang, L. Zhou, J. Zhang, Y.-Y. Fu, X. Zhang, C. Yu, S.-K. Sun and X.-P. Yan, Nanoscale, 2016, 8, 16204-16211.

7 L. Dykman and N. Khlebtsov, Chem. Soc. Rev., 2012, 41, 2256-2282.

8 R. Sardar, A. M. Funston, P. Mulvaney and R. W. Murray, Langmuir, 2009, 25, 13840-13851.

9 P. Ghosh, G. Han, M. De, C. K. Kim and V. M. Rotello, Adv. Drug Delivery Rev., 2008, 60, 1307-1315.

10 B. Duncan, C. Kim and V. M. Rotello, J. Controlled Release, 2010, 148, 122-127.

11 R. D. Ross, L. E. Cole, J. M. R. Tilley and R. K. Roeder, Chem. Mater., 2014, 26, 1187-1194.

12 S. Mallidi, T. Larson, J. Tam, P. P. Joshi, A. Karpiouk, K. Sokolov and S. Emelianov, Nano Lett., 2009, 9, 2825-2831.

13 E. Boisselier and D. Astruc, Chem. Soc. Rev., 2009, 38, 1759-1782.

14 S. M. Lee, H. J. Kim, Y. J. Ha, Y. N. Park, S. K. Lee, Y. B. Park and K. H. Yoo, ACS Nano, 2013, 7, 50-57.

15 H. Shi, Z. Wang, C. Huang, X. Gu, T. Jia, A. Zhang, Z. Wu, L. Zhu, X. Luo, X. Zhao, N. Jia and F. Miao, Small, 2016, 12, 3995-4006.

16 S. S. Lucky, K. C. Soo and Y. Zhang, Chem. Rev., 2015, 115, 1990-2042.

17 S. H. Voon, L. V. Kiew, H. B. Lee, S. H. Lim, M. I. Noordin, A. Kamkaew, K. Burgess and L. Y. Chung, Small, 2014, 10, 4993-5013.

18 M. Lee, H. Lee, N. Vijayakameswara Rao, H. S. Han, S. Jeon, J. Jeon, S. Lee, S. Kwon, Y. D. Suh and J. H. Park, J. Mater. Chem. B, 2017, 5, 7319-7327.
19 N. S. Abadeer and C. J. Murphy, J. Phys. Chem. C, 2016, 120, 4691-4716.

20 F. Jabeen, M. Najam-ul-Haq, R. Javeed, C. Huck and G. Bonn, Molecules, 2014, 19, 20580.

21 M. S. Khan, M. L. Bhaisare, J. Gopal and H.-F. Wu, J. Ind. Eng. Chem., 2016, 36, 49-58.

22 L. Fang, W. Wang, Y. Liu, Z. Xie and L. Chen, J. Mater. Chem. $B, 2017,5,8833-8838$.

23 R. R. Arvizo, S. Rana, O. R. Miranda, R. Bhattacharya, V. M. Rotello and P. Mukherjee, J. Nanomed. Nanotechnol., 2011, 7, 580-587.

24 S. Bhattacharyya, R. A. Kudgus, R. Bhattacharya and P. Mukherjee, Pharm. Res., 2011, 28, 237-259.

25 S. A. Grant, C. S. Spradling, D. N. Grant, D. B. Fox, L. Jimenez, D. A. Grant and R. J. Rone, J. Biomed. Mater. Res., Part A, 2014, 102, 332-339.

26 M. Akrami, S. Balalaie, S. Hosseinkhani, M. Alipour, F. Salehi, A. Bahador and I. Haririan, Sci. Rep., 2016, 6, 31030.

27 M.-Y. Lee, J.-A. Yang, H. S. Jung, S. Beack, J. E. Choi, W. Hur, H. Koo, K. Kim, S. K. Yoon and S. K. Hahn, ACS Nano, 2012, 6, 9522-9531.

28 R. A. Kudgus, A. Szabolcs, J. A. Khan, C. A. Walden, J. M. Reid, J. D. Robertson, R. Bhattacharya and P. Mukherjee, PLoS One, 2013, 8, e57522.

29 S. A. Jensen, E. S. Day, C. H. Ko, L. A. Hurley, J. P. Luciano, F. M. Kouri, T. J. Merkel, A. J. Luthi, P. C. Patel, J. I. Cutler, W. L. Daniel, A. W. Scott, M. W. Rotz, T. J. Meade, D. A. Giljohann, C. A. Mirkin and A. H. Stegh, Sci. Transl. Med., 2013, 5, 209 ra152.

30 R. Kotcherlakota, D. J. Srinivasan, S. Mukherjee, M. M. Haroon, G. H. Dar, U. Venkatraman, C. R. Patra and V. Gopal, J. Mater. Chem. B, 2017, 5, 7082-7098.

31 S. M. Taghdisi, N. M. Danesh, H. R. Beheshti, M. Ramezani and K. Abnous, Nanoscale, 2016, 8, 3439-3446.

32 G. Paramasivam, N. Kayambu, A. M. Rabel, A. K. Sundramoorthy and A. Sundaramurthy, Acta Biomater., 2017, 49, 45-65.

33 O. S. Muddineti, B. Ghosh and S. Biswas, Int. J. Pharm., 2015, 484, 252-267.

34 L. Chen and H.-A. Klok, Soft Matter, 2013, 9, 10678-10688.

35 Z. Chen, L. Zhang, Y. He, Y. Shen and Y. Li, Small, 2015, 11, 952-962.

36 L. Luo, Y. Bian, Y. Liu, X. Zhang, M. Wang, S. Xing, L. Li and D. Gao, Small, 2016, 12, 4103-4112.

37 R. R. Costa, M. Alatorre-Meda and J. F. Mano, Biotechnol. $A d v .$, 2015, 33, 1310-1326.

38 S. M. Oliveira, V. E. Santo, M. E. Gomes, R. L. Reis and J. F. Mano, Biomaterials, 2015, 48, 56-65.

39 F.-X. Xiao, M. Pagliaro, Y.-J. Xu and B. Liu, Chem. Soc. Rev., 2016, 45, 3088-3121.

40 S. J. Rego, A. C. Vale, G. M. Luz, J. F. Mano and N. M. Alves, Langmuir, 2016, 32, 560-568.

41 J. Borges and J. F. Mano, Chem. Rev., 2014, 114, 8883-8942. 42 H. K. No, N. Y. Park, S. H. Lee and S. P. Meyers, Int. J. Food Microbiol., 2002, 74, 65-72.

43 A. T. Paulino, A. G. B. Pereira, A. R. Fajardo, K. Erickson, M. J. Kipper, E. C. Muniz, L. A. Belfiore and E. B. Tambourgi, Carbohydr. Polym., 2012, 90, 1216-1225. 
44 M. Ishihara, K. Nakanishi, K. Ono, M. Sato, M. Kikuchi, Y. Saito, H. Yura, T. Matsui, H. Hattori, M. Uenoyama and A. Kurita, Biomaterials, 2002, 23, 833-840.

45 H. J. Lam, S. Patel, A. J. Wang, J. Chu and S. Li, Tissue Eng., Part A, 2010, 16, 2641-2648.

46 A. E. Mochalova, S. Koryagin, E. V. Salomatina, K. V. Apryatina and L. A. Smirnova, J. Nanotechnol. Diagn. Treat., 2014, 2, 34-41.

47 C. J. Dowd, C. L. Cooney and M. A. Nugent, J. Biol. Chem., 1999, 274, 5236-5244.

48 D. Gospodarowicz, N. Ferrara, L. Schweigerer and G. Neufeld, Endocr. Rev., 1987, 8, 95-114.

49 J. Slavin, Cell Biol. Int., 1995, 19, 431-444.

50 N. Turner and R. Grose, Nat. Rev. Cancer, 2010, 10, 116-129.

51 Y.-R. Yun, J. E. Won, E. Jeon, S. Lee, W. Kang, H. Jo, J.-H. Jang, U. S. Shin and H.-W. Kim, J. Tissue Eng., 2010, 218142.

52 R. Flaumenhaft, D. Moscatelli and D. B. Rifkin, J. Cell Biol., 1990, 111, 1651-1659.

53 X. Li, G. Su, J. Wang, Z. Zhou, L. Li, L. Liu, M. Guan, Q. Zhang and H. Wang, Osteoarthr. Cartil., 2013, 21, 1567-1575.

54 S. Hankemeier, M. Keus, J. Zeichen, M. Jagodzinski, T. Barkhausen, U. Bosch, C. Krettek and M. Van Griensven, Tissue Eng., 2005, 11, 41-49.

55 T. Fujisato, T. Sajiki, Q. Liu and Y. Ikada, Biomaterials, 1996, 17, 155-162.

56 M. Paciaroni and J. Bogousslavsky, Expert Opin. Biol. Ther., 2011, 11, 1533-1541.

57 H. Maehara, S. Sotome, T. Yoshii, I. Torigoe, Y. Kawasaki, Y. Sugata, M. Yuasa, M. Hirano, N. Mochizuki, M. Kikuchi, K. Shinomiya and A. Okawa, J. Orthop. Res., 2010, 28, 677-686.

58 K. S. Hong, E. C. Kim, S. H. Bang, C. H. Chung, Y. I. Lee, J. K. Hyun, H. H. Lee, J. H. Jang, T. I. Kim and H. W. Kim, J. Biomed. Mater. Res., Part A, 2010, 94, 1187-1194.

59 H. Lee, S. Lim, M. S. Birajdar, S.-H. Lee and H. Park, Int. J. Biol. Macromol., 2016, 93, 1559-1566.

60 H. Uchi, A. Igarashi, K. Urabe, T. Koga, J. Nakayama, R. Kawamori, K. Tamaki, H. Hirakata, T. Ohura and M. Furue, Eur. J. Dermatol., 2009, 19, 461-468.

61 K. Okabe, R. Hayashi, N. Aramaki-Hattori, Y. Sakamoto and K. Kishi, Modern Plastic Surgery, 2013, 3, 108-112.

62 Z. Poon, J. B. Lee, S. W. Morton and P. T. Hammond, Nano Lett., 2011, 11, 2096-2103.

63 Y. Yao and Y. Wang, J. Cell. Biochem., 2013, 114, 1223-1229.

64 P. E. Tyllianakis, S. E. Kakabakos, G. P. Evangelatos and D. S. Ithakissios, Appl. Biochem. Biotechnol., 1992, 38, 15-25.

65 J. Turkevich, P. C. Stevenson and J. Hillier, Discuss. Faraday Soc., 1951, 11, 55-75.

66 N. Monteiro, A. Martins, R. Pires, S. Faria, N. A. Fonseca, J. N. Moreira, R. L. Reis and N. M. Neves, Biomater. Sci., 2014, 2, 1195-1209.

67 C. Oliveira, A. R. Costa-Pinto, R. L. Reis, A. Martins and N. M. Neves, Biomacromolecules, 2014, 15, 2196-2205.

68 I. Reviakine, D. Johannsmann and R. P. Richter, Anal. Chem., 2011, 83, 8838-8848.
69 M. Lundin, F. Solaqa, E. Thormann, L. Macakova and E. Blomberg, Langmuir, 2011, 27, 7537-7548.

70 W. Yuan, J. Fu, K. Su and J. Ji, Colloids Surf., B, 2010, 76, 549-555.

71 Q. Ruan, Y. Zhu, F. Li, J. Xiao, Y. Zeng and F. Xu, J. Colloid Interface Sci., 2009, 333, 725-733.

72 R. Teixeira, R. L. Reis and I. Pashkuleva, Colloids Surf., B, 2016, 145, 567-575.

73 M. Lundin, L. Macakova, A. Dedinaite and P. Claesson, Langmuir, 2008, 24, 3814-3827.

74 T. Crouzier and C. Picart, Biomacromolecules, 2009, 10, 433-442.

75 S. Labala, P. K. Mandapalli, A. Kurumaddali and V. V. K. Venuganti, Mol. Pharmaceutics, 2015, 12, 878-888.

76 S. Amorim, A. Martins, N. M. Neves, R. L. Reis and R. A. Pires, J. Mater. Chem. B, 2014, 2, 6939-6946.

77 I. C. Sun, J. H. Na, S. Y. Jeong, D. E. Kim, I. C. Kwon, K. Choi, C. H. Ahn and K. Kim, Pharm. Res., 2014, 31, 1418-1425.

78 D. R. Bhumkar, H. M. Joshi, M. Sastry and V. B. Pokharkar, Pharm. Res., 2007, 24, 1415-1426.

79 R. Novoa-Carballal, C. Silva, S. Moller, M. Schnabelrauch, R. L. Reis and I. Pashkuleva, J. Mater. Chem. B, 2014, 2, 4177-4184.

80 E. Lallana, J. M. Rios de la Rosa, A. Tirella, M. Pelliccia, A. Gennari, I. J. Stratford, S. Puri, M. Ashford and N. Tirelli, Mol. Pharmaceutics, 2017, 14, 2422-2436.

81 S. Al-Qadi, M. Alatorre-Meda, E. M. Zaghloul, P. Taboada and C. Remunán-López, Colloids Surf., B, 2013, 103, 615-623.

82 F. A. Oyarzun-Ampuero, J. Brea, M. I. Loza, D. Torres and M. J. Alonso, Int. J. Pharm., 2009, 381, 122-129.

83 T. Sato, M. Nakata, Z. Yang, Y. Torizuka, S. Kishimoto and M. Ishihara, J. Gene Med., 2017, 19, e2968.

84 L. Yang, S. Gao, S. Asghar, G. Liu, J. Song, X. Wang, Q. Ping, C. Zhang and Y. Xiao, Int. J. Biol. Macromol., 2015, 72, 1391-1401.

85 F. Wang, S. Yang, J. Yuan, Q. Gao and C. Huang, J. Biomater. Appl., 2016, 31, 3-12.

86 J. Candiello, T. Richardson, K. Padgaonkar, K. Task, P. N. Kumta and I. Banerjee, J. Mater. Chem. B, 2016, 4, 3575-3583.

87 P. Sun, W. Huang, M. Jin, Q. Wang, B. Fan, L. Kang and Z. Gao, Int. J. Nanomed., 2016, 11, 4931-4945.

88 O. T. Marisca, K. Kantner, C. Pfeiffer, Q. Zhang, B. Pelaz, N. Leopold, W. J. Parak and J. Rejman, Nanomaterials, 2015, 5, 1418-1430.

89 E. E. Connor, J. Mwamuka, A. Gole, C. J. Murphy and M. D. Wyatt, Small, 2005, 1, 325-327.

90 C. Freese, M. I. Gibson, H.-A. Klok, R. E. Unger and C. J. Kirkpatrick, Biomacromolecules, 2012, 13, 1533-1543.

91 A. Regiel-Futyra, M. Kus-Liśkiewicz, V. Sebastian, S. Irusta, M. Arruebo, G. Stochel and A. Kyzioł, ACS Appl. Mater. Interfaces, 2015, 7, 1087-1099.

92 Y. Uteza, J. S. Rouillot, A. Kobetz, D. Marchant, S. Pecqueur, E. Arnaud, H. Prats, J. Honiger, J. L. Dufier, M. Abitbol and M. Neuner-Jehle, Proc. Natl. Acad. Sci. U. S. A., 1999, 96, 3126-3131. 